\title{
Investigating the Relationship between Sprint and Jump Performances with Velocity and Power Parameters during Propulsive Phase of the Loaded-squat Jump Exercise
}

\author{
İbrahim CAN \\ School of Physical Education and Sport, Gümüşhane University, Gümüşhane, Turkey
}

Copyright $(2018$ by authors, all rights reserved. Authors agree that this article remains permanently open access under the terms of the Creative Commons Attribution License 4.0 International License

\begin{abstract}
The purpose of this study was to investigate the relationship between sprint and jump performance with velocity parameters in the loaded-squat jump exercise ( $\mathrm{SQ}_{\text {Loaded }}$ ). In accordance with this purpose, a total of 13 athletes competing in martial sports have participated in this study voluntarily. In this study, sprint tests, vertical jump (VJ), standing long jump (SLJ) tests and one repetition maximal strength test were applied. In order to determine velocity and power parameters, SQ $Q_{\text {Loaded }}$ exercise was applied by using an external load that corresponds to $40 \%$ of body weights of the subjects via an isoinertial velocity transducer (T-Force dynamic measurement system) and values of mean propulsive velocity (MPV), peak velocity (PV), mean propulsive power (MPP) and peak power (PP) were obtained. Descriptive statistics, Spearman correlation analysis and Shapiro-Wilk normality tests were used for data assessment. It has been concluded that there is no statistically significant relation between 10,20 and 30 meter sprint times and the values of $\operatorname{MPV}(\mathrm{r}=-, 332 ; \mathrm{r}=$ ,$- 375 ; \mathrm{r}=-, 446 ; \mathrm{p}>.05$ respectively), $\mathrm{PV}(\mathrm{r}=-, 058 ; \mathrm{r}=-, 118$; $\mathrm{r}=-, 165 ; \mathrm{p}>.05$ respectively), MPP $(\mathrm{r}=-, 285 ; \mathrm{r}=-, 482 ; \mathrm{r}=$ ,$- 485 ; \mathrm{p}>.05$ respectively) and $\mathrm{PP}(\mathrm{r}=-, 205 ; \mathrm{r}=-, 512 ; \mathrm{r}=$ ,$- 391 ; \mathrm{p}>.05$ respectively) during $\mathrm{SQ}_{\text {Loaded }}$ exercise. In addition, while no statistically significant relation has been obtained between the VJ and SLJ values of the participants and MPV ( $\mathrm{r}=, 496 ; \mathrm{r}=, 429 ; \mathrm{p}>.05$ respectively) and $\mathrm{PV}$ $(\mathrm{r}=, 300 ; \mathrm{r}=, 223 ; \mathrm{p}>.05$ respectively) values during propulsive stage of $\mathrm{SQ}_{\text {Loaded }}$ exercise, it has been ascertained that there is a statistically positive and significant relation between the values of $\operatorname{MPP}(\mathrm{r}=, 620$; $\mathrm{r}=, 580 ; \mathrm{p}>.05$ respectively) and $\mathrm{PP}(\mathrm{r}=, 678 ; \mathrm{r}=, 572 ; \mathrm{p}<.05$ respectively). In conclusion, it can be suggested that lifting velocity and power values don't have a positive effect on short sprint performance; however power values affect the vertical jump and standing long jump performances
\end{abstract}

positively.

Keywords Power, Velocity, Jump, Sprint

\section{Introduction}

Power being among the important factors of athletic performance possesses a time component and denotes the mechanical amount defined as the temporal rate of work done (power=work/time) and it generally depends on the ability of creating the maximum possible force (maximal force) $[1,2]$. In other words, if two athletes have similar maximal strengths, the individual who exerts the force at a higher speed (or in shorter time) will have a distinct advantage in performance of anaerobic movements [3]. The performance success of many athletic actions is often a matter of how much power will be applied to objects (such as ground, ball, or sports equipment) [1]; the success during a particular athletic work completed in a short time depends on the power efficiency capacity of the athletes [4].

Today, isometric, isokinetic and isoinertial methods are used for power evaluation [5] and the most commonly used parameters are mean power (MP), mean propulsive power (MPP) and peak power (PP). The load that maximizes the mechanical efficiency depends on such parameters as MP, MPP and PP [6,7]. These parameters can be used in order to create a central variable thought to be important for power and performance in explosive type of studies. This variable is the training load that maximizes the mechanical efficiency of the muscle $[5,6,8]$. MP indicates mean values obtained from the total of all positive values in concentric stage divided to the number of data reached within the range of motion. MPP denotes the mean power efficiency 
in propulsive stage of concentric phase. PP is defined as production of maximal power within the range of all concentric muscular contraction and is expressed as the peak power reflecting the higher instantaneous power generation within a period of $1 / \mathrm{m} \cdot \mathrm{s}^{-1}$ without observing a certain movement. Some authors define this capacity as the moment reflecting the maximal mechanical performance an athlete can generate during a movement and reached in threshold muscular performance [9].

The velocity, which is a vector quantity, is the temporal rate of change in positions [10]. The velocity of a muscle's concentric contraction is inversely related to the applied load or external force. When the applied force is zero, the contraction rate of the muscle is the greatest. When the force increases to a level equal to the maximal force that strains the muscle, the contraction rate becomes zero [11]. In other words, the heavier the weight is, the higher an increase becomes in the force produced by the muscle and a decrease in velocity of movement. This situation is also correct experimentally. When an athlete is asked to perform bench press (BP) with the possible maximal weight, she/he will move the weight very slowly. However, if $\mathrm{s} / \mathrm{he}$ is asked to perform the movement in the half of one repetition maximal (1RM), the athlete will move the bar at a faster velocity [12]. Every increase of $5 \%(30-100 \%$ of $1 \mathrm{RM})$ in relative load (\%1RM) causes a difference within the range of $0.07-0.09 \mathrm{~m} \cdot \mathrm{s}^{-1}$. Movement velocity is a variable that may be more interesting to follow the intensity of exercise. Perhaps the current speed at each turn may be the best reference for the actual amount of effort the athlete carries out [13].

Sprint is the ability of running at a maximal or near maximum speed in a very short period of time [14] and it is an important indicator for the success in many sports [15]. For this reason, the ability of sprint is a complex skill requiring appropriate motor coordination between joints and muscles [16]. Most researchers and practitioners point out that sprinting ability at very short distances $(5$ or $10 \mathrm{~m})$ requires specific force characteristics and running technique while very short sprints generally require a larger concentric muscle contraction contribution and knee extensor activity [17].

Jumping performance, known as jumping up horizontally as far as possible and vertically as high as possible, is regarded as one of the most important criteria expressing the muscle force of lower body $[18,19]$. Jumping is an attribute which contains complex exercise and it depends on the individual's leg muscle strength, explosive power, the flexibility of the muscles engaged in jumping movement and the ability to jump. Jumping ability is an important performance indicator for many sports branches such as basketball, football and volleyball [20]. Jumping tests are used as a measurement of lower body strength in such branches as football where a high level of lower body muscle strength is necessary and in order to determine the development of jumping performance in such branches as basketball, handball and volleyball where the jumping movement contributes to athletic performance [21].

In literature, it is observed that the current relation between the velocity and power parameters of in concentric phase of the full squat movement with the sprint and jumping performance $[22,23,24,25]$ or the relation between the velocity parameters in countermovement jumping movement and short sprint performance [17]. However, no studies exist analyzing the relation between the velocity and power parameters during loaded-squat jump movement with the sprint and jumping performance. Considering that sprint and jump performance is accepted as important components in many sports branches and these components are very important elements for athletic success $[7,26]$, determining some performance attributes and the velocity and power values of athletes during jumping and revealing the relation between them may contribute to training of these attributes. For this reason, the purpose of this study is to analyze the relation of velocity (MPV and PV) and power (MPP and PP) values during loaded-squat jump exercise with sprint $(10,20$ and $30 \mathrm{~m}$ ) and jumping ability (vertical and horizontal).

\section{Material and Method}

\section{Participants}

A total of 13 athletes (age: 21.6 \pm 2.10 ; height: $180.6 \pm 3.40 \mathrm{~cm}$; weight: $73.4 \pm 6.57 \mathrm{~kg}$ ) competing in martial arts voluntarily participated in this study. Medical condition of the participants was good and no one was using a medication that could negatively affect the analyzed variables. Before initiating the study, all participants were informed in detail about the purpose of study, test procedures, potential risks and benefits of the research and then the participants signed an approval document indicating that they would participate in the study voluntarily.

\section{Procedures}

All subjects participating in this study consist of the athletes who have completed their strength training programs in the past. The measurement of the participants was performed on 3 different days with one (1) day of rest. On the first day, the participants performed loaded-squat jump exercise with the loads equivalent to $40 \%$ of their own body weight considering their physical characteristics. On the second day, participants were performed to short sprint running (10. 20 and 30 meter), vertical jump and standing long jump tests. On the third and last day, the subjects were performed one repetition maximal test (1RM) in the full back squat exercise.

Participants' height and body weight measurements were 
obtained using a Seca 769 electronic measuring instrument (Seca Corporation, Hamburg, Germany) with an accuracy of $0.001 \mathrm{~m}$ and $0.01 \mathrm{~kg}$, respectively. The an external load corresponding to $40 \%$ of their body weight was calculated after the physical characteristics of the participates were determined. A total of 20-minute standard warm-up exercises composed of 15 minutes of general (10 minutes of running after 5 minutes of lower body stretching) and 5 minutes of special exercises (squat tries at submaximal level) were applied to the participants before applying weighted jump squat exercises. Following the warm-up, loaded-squat jump ( $\left.\mathrm{SJ}_{\text {Loaded }}\right)$ test was applied to the subjects by using free weights with an external load equivalent to $40 \%$ of body weight. In this test protocol, subjects were asked to bring their knees to the flexion until their thighs were parallel to ground from the static position, to jump as fast as possible without losing contact between their shoulders and bar following the start command and to repeat it 3 times [27]. These movements were repeated when these requirements were not fulfilled. Since, body weight must be moved in addition to the external load during the loaded-squat jump test and parameters such as velocity and power must be determined thanks to the ability to accelerate the total mass (external load and body weight) of the subject [28].

A linear transducer (T-Force Dynamic Measurement System; Ergotech Consulting S.L, Murcia, Spain) was connected to the last section of the bar to determine velocity and power parameters. Use of this system is suitable particularly for typical weight lifting exercises or any resistance training exercise in which it is obligatory to overcome a load (constant mass) moving along a vertical axis against gravity. The system consists of an electromechanical hardware (velocity sensor and interface), a special computer program (T-Force system software) that manages this software and a hook connected to the weight lifting. The velocity sensor is usually placed on the ground and measures the velocity of the lifted loads by measuring how quickly the 2-meter cable is pulled and released via a tachogenerator with a high sensitivity within the aluminum body. In other words, the sensor provides a direct power in proportion to the movement of the cable and allows a direct determination of the velocity at which the movement is made. The cable is made of nylon-coated stainless steel and has a diameter of $0.50 \mathrm{~mm}$. The voltage of the wire (5 N) can withstand large accelerations, so using this system for sudden athletic movements such as vertical jumping, pull and lift does not cause any problems. The computer transmission interface includes an electronic data acquisition panel equipped with 14-bit resolution. It is connected to the computer via a USB port which allows very fast and reliable data transfer. The sampling frequency of the data obtained is fixed at $1000 \mathrm{~Hz}$. This means that instantaneous speed data in each $\mathrm{ms}$ is obtained. A specifically designed hook is used to connect the workout weight dumbbell to the power converter cable $[6,7]$.
After a 10-minute warm-up, the participants performed a vertical jump (VJ) and a standing long jump (SLJ) tests. In the vertical jump test, the arm length of athletes was determined in front of the test platform and it was stated that they should jump as high as possible. At the end of the test, the distance between the jump height and arm length of the subjects was calculated and the vertical jump values were determined as $\mathrm{cm}$. Standing long jump test was applied in measurement of leg muscle strength. In the application of the test, the athletes were requested to open their legs in the shoulder width and to jump forward by getting support from the knees in a position that their toes not exceeding the defined area (starting line). The distance between the toes of the subjects in the defined area and the heel of the foot touching the ground was calculated and recorded as $\mathrm{cm}$ [29]. Both tests were performed two times by giving adequate rest time to allow the athletes recover fully and the best test values were recorded for the performance of statistical analyses.

In order to measure the sprint performances of the participants, sprint tests were applied to the subjects at 10

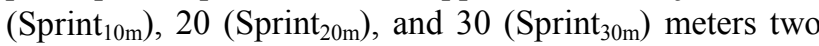
times from the static position $(0$ meter behind the first photocell sensor) with a 3-minute rest period (to ensure full recovery) and the best sprint times were recorded for statistical analysis.

$1 \mathrm{RM}$ values of the participants for full back squat exercise $\left(1 \mathrm{RM}_{\mathrm{SQ}}\right)$ were obtained via the method designed by Beachle et al. [30] over a Smith machine (Esjim IT7001, Eskisehir, Turkey). In the application of full squat movement, a procedure designed by Earle and Beachle [31] was used. In this procedure, subjects were asked to place weight halter with the shoulder-backed alignment (high bar position) by grapping the weight halter with an inward-facing grip slightly wider than the shoulder width. Participants' feet were slightly more open than the shoulder width and their feet faced towards a little outside when they began to descend. Subjects reached the lowest point of descent when their thighs were parallel to each other and lifted the weight halter with continuous movement without help. One assistant was placed on both sides of the weight lifter for safety. It was stated that during the application of the full squat movement, the participants were told to inhale while getting the weight halter down and to exhale while lifting it. Concentric phase was performed at maximal velocity and eccentric phase at a controlled velocity.

\section{Statistical Analyses}

All variables were expressed as mean and standard deviation. Spearman's correlation coefficient analysis was used in order to determine that velocity and power values obtained in concentric phase of squat exercise don't have any statistical relation with the short sprint and jumping performance. SPSS version 16.0 (SPSS Inc, Chicago, IL) was used for all statistical calculations and the significance 
level was accepted as $\mathrm{p}<.05$.

\section{Results}

The results of the participants concerning some variables during the $\mathrm{SJ}_{\text {Loaded }}$ exercise are indicated in table 1 and descriptive statistical results for some performance parameters are summarized in table 2 . The results of the correlation analysis between the velocity and power parameters during the propulsive phase of $\mathrm{SJ}_{\text {Loaded }}$ exercise and some performance values are given in table 3 .

According to the analysis results, it was determined that there was no statistically significant relation between 10 , 20 and 30 meter sprint times and MPV $(\mathrm{r}=-, 332 ; \mathrm{r}=-, 375$; $\mathrm{r}=-, 446 ; \mathrm{p}>0.05$, respectively), $\mathrm{PV}(\mathrm{r}=-, 058 ; \mathrm{r}=-, 118 ; \mathrm{r}=$ ,$- 165 ; \mathrm{p}>0.05$, respectively), MPP $(\mathrm{r}=-, 285 ; \mathrm{r}=-, 482 ; \mathrm{r}=$ ,$- 485 ; \mathrm{p}>0.05$, respectively) and PP $(\mathrm{r}=-, 205 ; \mathrm{r}=-, 512 ; \mathrm{r}=$ ,$- 391 ; \mathrm{p}>0.05$, respectively) values during the propulsive phase of $\mathrm{SJ}_{\text {Loaded }}$ exercise (table 3). It was determined that there was no statistically significant relation between VJ and SLJ values of the participants and MPV $(\mathrm{r}=, 496$; $\mathrm{r}=, 429 ; \mathrm{p}>0.05$, respectively) and $\mathrm{PV}(\mathrm{r}=, 300 ; \mathrm{r}=, 223$; $\mathrm{p}>0.05$, respectively) values during propulsive phase of $\mathrm{SJ}_{\text {Loaded }}$ exercise while a statistically positive and significant relation was established between MPP $(\mathrm{r}=, 620$; $\mathrm{r}=, 580 ; \mathrm{p}>0.05$, respectively) and $\mathrm{PP}(\mathrm{r}=, 678 ; \mathrm{r}=, 572$; $\mathrm{p}<0.05$, respectively) values (table 3 ). While no statistically significant relation was ascertained between the $1 \mathrm{RM}_{\mathrm{SQ}}$ values of the participants and MPV $(\mathrm{r}=, 426$; $\mathrm{p}>0.05)$ and PV ( $r=, 267 ; \mathrm{p}>0.05)$ values during the propulsive phase of $\mathrm{SJ}_{\text {Loaded }}$ exercise, a statistically positive and highly significant relation was found between MPP $(\mathrm{r}=, 733 ; \mathrm{p}>0.01)$ and $\mathrm{PP}(\mathrm{r}=, 796 ; \mathrm{p}<0.01)$ values (table 3$)$.. No statistically significant relation was determined between VJ $(r=-, 068 ; p>0.05)$, SLJ $(r=, 028 ; p>0.05)$, $1 \mathrm{RM}_{\mathrm{SQ}}(\mathrm{r}=-, 338 ;>0.05)$ with Sprint $\mathrm{tom}_{10 \mathrm{~m}}$ and between VJ $(r=-, 506 ; p>0.05)$, SLJ $(r=-, 393 ; p>0.05)$ with Sprint $30 \mathrm{~m}$. However, a statistically negative and significant relation was ascertained between VJ $(\mathrm{r}=-, 685 ; \mathrm{p}<0.01)$, SLJ ( $\mathrm{r}=$ $-, 579 ; \mathrm{p}<0.05), 1 \mathrm{RM}_{\mathrm{SQ}}(\mathrm{r}=-, 824 ; \mathrm{p}<0.01)_{\text {with }}$ Sprint $_{20 \mathrm{~m}}$ and between $1 \mathrm{RM}_{\mathrm{SQ}}(\mathrm{r}=-, 678 ; \mathrm{p}<0.01)$ and Sprint $_{30 \mathrm{~m}}($ table 3$)$.
Table 1. Descriptive Statistical Results For Some Variables During Loaded-Squat Jump Exercise of Participates

\begin{tabular}{|c|c|c|c|c|}
\hline Variables & $\mathrm{n}$ & Minimal & Maximal & Mean $( \pm \mathrm{sd})$ \\
\hline MPV $\left(\mathrm{m} / \mathrm{sec}^{-1}\right)$ & 13 & 1,46 & 1,81 & $1,58 \pm, 10$ \\
\hline PV $\left(\mathrm{m} / \mathrm{sec}^{-1}\right)$ & 13 & 2,43 & 2,94 & $2,63 \pm, 15$ \\
\hline MPP $(\mathrm{W})$ & 13 & 529,70 & 874,90 & $687,96 \pm 101,3$ \\
\hline PP $(\mathrm{W})$ & 13 & 918,00 & 1461,60 & $1185,5 \pm 168,3$ \\
\hline Displacement $(\mathrm{cm})$ & 13 & 73,72 & 96,55 & $87,2 \pm 6,45$ \\
\hline Time $(\mathrm{ms})$ & 13 & 549,00 & 715,00 & $617,4 \pm 46,8$ \\
\hline Load $(\mathrm{kg})$ & 13 & 25,00 & 32,50 & $29,5 \pm 2,94$ \\
\hline
\end{tabular}

Table 2. Descriptive Statistical Results For Participate's Some Variables

\begin{tabular}{|c|c|c|c|c|}
\hline Variables & $\mathrm{n}$ & Minimal & Maximal & Mean $( \pm \mathrm{sd})$ \\
\hline 10 meter $(\mathrm{sec})$ & 13 & 1,52 & 1,70 & $1,61 \pm, 05$ \\
\hline 20 meter (sec) & 13 & 2,52 & 2,87 & $2,65 \pm, 12$ \\
\hline 30 meter (sec) & 13 & 3,77 & 4,19 & $3,97 \pm, 14$ \\
\hline $\begin{array}{c}\text { Vertical } \\
\text { Jump(cm) }\end{array}$ & 13 & 47,00 & 70,00 & $56,07 \pm 6,33$ \\
\hline $\begin{array}{c}\text { Standing Long } \\
\text { Jump (sn) }\end{array}$ & 13 & 227,00 & 270,00 & $242,46 \pm 13,75$ \\
\hline $\begin{array}{c}\text { 1RM in Full } \\
\text { Squat (kg) }\end{array}$ & 13 & 75,00 & 140,00 & $111,15 \pm 21,80$ \\
\hline
\end{tabular}

\section{Discussion}

The purpose of this study is to analyze the relation between power and velocity parameters during loaded-squat jump exercise with the sprint and jumping performance of the athletes competing in martial arts. As much as we examined the literature, there is no study investigating the relation between sprint and jump performance with power and velocity parameters in SQLoaded exercise measured using a linear velocity transducer. One repetition maximum (1RM) is expressed as the maximal force an individual can lift in a lump in a specific exercise or the maximal force she/he can produce [32]. In this study, 1RM strength values of the athletes competing in martial sports in full back squat exercise were obtained as $111( \pm 21.8 \mathrm{~kg})$. There are many studies in literature examining the $1 \mathrm{RM}_{\mathrm{SQ}}$ strength values of amateur or professional athletes in different branches $[22,25,28,33,34,35,36,37,38,39]$. 
Table 3. Results of Spearman Correlation Analysis between Participate's Some Performance Values with Velocity and Power Parameters During Propulsive Phase of the Loaded-Squat Jump Exercise

\begin{tabular}{|c|c|c|c|c|c|c|c|c|c|c|}
\hline & & $\mathrm{PV}$ & MPP & $\mathrm{PP}$ & Sprint $_{10}$ & Sprint $_{20}$ & Sprint $_{30}$ & $\mathrm{VJ}$ & SLJ & $1 \mathrm{RM}_{\mathrm{SQ}}$ \\
\hline \multirow{3}{*}{ MPV } & $\mathrm{r}$ &, $775^{* *}$ & ,599* &, 418 &,- 332 &,- 375 &,- 446 & ,496 & ,429 &, 426 \\
\hline & $\mathrm{p}$ & ,002 &, 031 & , 156 & ,267 & ,207 & , 126 & ,085 & ,143 & , 146 \\
\hline & $\mathrm{n}$ & 13 & 13 & 13 & 13 & 13 & 13 & 13 & 13 & 13 \\
\hline \multirow{3}{*}{ PV } & $\mathrm{r}$ & &, 544 & ,451 &,- 058 &,- 118 &,- 165 & ,300 & ,223 & ,267 \\
\hline & $\mathrm{p}$ & &, 055 &, 122 &, 850 &, 700 & ,589 &, 319 &, 464 & ,377 \\
\hline & $\mathrm{n}$ & & & 13 & 13 & 13 & 13 & 13 & 13 & 13 \\
\hline \multirow{3}{*}{ MPP } & $\mathrm{r}$ & & &, $934^{* *}$ &,- 285 &,- 482 &,- 485 &, $620^{*}$ &, $580^{*}$ &, $733^{* *}$ \\
\hline & $\mathrm{p}$ & & &, 000 & ,345 & ,095 & ,093 &, 024 &, 038 &, 004 \\
\hline & $\mathrm{n}$ & & & 13 & 13 & 13 & 13 & 13 & 13 & 13 \\
\hline \multirow{3}{*}{ PP } & $\mathrm{r}$ & & & &,- 205 &,- 512 &,- 391 & $678^{*}$ &, $572^{*}$ &, $796^{* *}$ \\
\hline & $\mathrm{p}$ & & & &, 502 &, 073 & , 186 &, 011 & ,041 & ,001 \\
\hline & $\mathrm{n}$ & & & & 13 & 13 & 13 & 13 & 13 & 13 \\
\hline \multirow{3}{*}{ Sprint $_{10 \mathrm{~m}}$} & $\mathrm{r}$ & & & & & ,344 &, $699^{* *}$ &,- 068 &, 028 &,- 338 \\
\hline & $\mathrm{p}$ & & & & & ,249 &, 008 & 825 & ,928 & ,258 \\
\hline & $\mathrm{n}$ & & & & & 13 & 13 & 13 & 13 & 13 \\
\hline \multirow{3}{*}{ Sprint $_{20 \mathrm{~m}}$} & $\mathrm{r}$ & & & & & &, $740^{* *}$ &,$- 685^{* *}$ &,$- 579^{*}$ &,$- 824^{* *}$ \\
\hline & $\mathrm{p}$ & & & & & &, 004 &, 010 &, 038 &, 001 \\
\hline & $\mathrm{n}$ & & & & & & 13 & 13 & 13 & 13 \\
\hline \multirow{3}{*}{ Sprint $_{30 \mathrm{~m}}$} & $\mathrm{r}$ & & & & & & &,- 506 &,- 393 &,$- 678^{*}$ \\
\hline & $\mathrm{p}$ & & & & & & & ,078 &, 184 &, 011 \\
\hline & $\mathrm{n}$ & & & & & & & 13 & 13 & 13 \\
\hline \multirow{3}{*}{ VJ } & $\mathrm{r}$ & & & & & & & &, $869^{* *}$ &, $790^{* *}$ \\
\hline & $\mathrm{p}$ & & & & & & & &, 000 & ,001 \\
\hline & $\mathrm{n}$ & & & & & & & & 13 & 13 \\
\hline \multirow{3}{*}{ SLJ } & $\mathrm{r}$ & & & & & & & & & ,609" \\
\hline & $\mathrm{p}$ & & & & & & & & & 027 \\
\hline & $\mathrm{n}$ & & & & & & & & & 13 \\
\hline
\end{tabular}

$* \mathrm{p}<0.05 ; * * \mathrm{p}<0.01$

MPV: mean propulsive velocity; PV: peak velocity; MPP: mean propulsive power; PP: peak power; Sprint ${ }_{10}: 10$ meter sprint; Sprint ${ }_{20}: 20$ meter sprint; Sprint ${ }_{30}$ : 30 meter sprint; VJ: vertical jump; SLJ: standing long jump; $1 \mathrm{RM}_{\mathrm{SQ}}$ : one repetition maximal in full squat movement

In a study conducted by Alcaraz et al. [37] on sprinters having at least 2 years of strength and 6 years of sprint training experience, mean $1 \mathrm{RM}_{\mathrm{SQ}}$ value was obtained as $199.7( \pm 59.1 \mathrm{~kg})$, while the values of $171.7 \mathrm{~kg}[34]$ and $119.5 \mathrm{~kg}$ [22] were obtained in elite soccer players. Concerning other studies conducted on football players, mean $1 \mathrm{RM}_{\mathrm{SQ}}$ values were $121 \pm 22.5 \mathrm{~kg}$ for NCAA $1^{\text {st }}$ league football players [36], 129.1 $\pm 11.4 \mathrm{~kg}$ in players of Celtic U17 team [35] and $170 \pm 21.7 \mathrm{~kg}$ for the players of the $1^{\text {st }}$ league [28]. In the study conducted by Iglesias-Soler et al. [38], mean $1 \mathrm{RM}_{\mathrm{SQ}}$ values of judoists having at least 18 months of strength training experience were obtained as $129.8( \pm 19.4 \mathrm{~kg})$. Izquierdo et al. [33] found these $1 \mathrm{RM}_{\mathrm{SQ}}$ values as 157 for weight-lifters $( \pm 18 \mathrm{~kg})$ and $134 \mathrm{~kg}$ for cyclists $( \pm 18 \mathrm{~kg})$. In a study conducted by Can [25] on amateur athletes, mean $1 \mathrm{RM}_{\mathrm{SQ}}$ values were obtained as 101 $( \pm 18.7 \mathrm{~kg})( \pm 18.7 \mathrm{~kg})$; while mean $1 \mathrm{RM}_{\mathrm{SQ}}$ values were found to be $141.8( \pm 17.4 \mathrm{~kg})$ in a study conducted by Çolak et al. [39] on university students performing weight exercises regularly. Regarding the results, it is observed that the values obtained differ by various populations. It can be alleged that this difference can result from the test procedures applied in studies, amateur or professional condition of athletes, sports branches or their participation in long-term force training protocols.

The success in many sports branches depends on the contribution of strength characteristic on jumping performance [40,41]. It was determined in this study that $1 \mathrm{RM}_{\mathrm{SQ}}$ strength value in full back squat exercise has a statistically significant relation with both vertical jumping $(r=, 790 ; p<0.01)$ and standing long jump $(r=, 609 ; p<0.05)$ performance. In literature, strong relations between strength and vertical jumping performance were demonstrated and it was alleged that strength characteristic positively affected the vertical jumping performance. In studies conducted on young female volleyball players [42] and also football players [34], a strong relation was ascertained between 1RM values in squat movement and jumping performance. However, statistically significant relation wasn't established between 1RM strength value and jump squat performance in half squat movement in the study conducted by Requena et al. [22] and also between 3RM strength and vertical jumping performance in another study conducted by Cronin and Hansen [43] on rugby players.

In this study, a significant relation was found between 20 
meter $(r=-, 824 ; \mathrm{p}<0.01)$ and 30 meter $(r=-, 678 ; \mathrm{p}<0.05)$ sprint times with 1 RM strength value in full back squat exercise, while no significant relation was ascertained with 10 meter sprint times $(r=-, 333 ; p>0.05)$. In literature, a statistically significant relation was found between 1RM strength value and sprint times in some studies, while no a significant relation was established in some other studies. In a study conducted by Wisloff et al. [34], a statistically significant relation was ascertained between the 1RM strength value in half squat exercise and 10 and 30 meter sprint times while no significant relation was found between 1RM strength value in squat movement and 10 and 40 meter sprint times in another study conducted by Harris et al. [44]. Similarly, Wilson et al. [45] found that no statistically significant relation existed between 1RM strength value and 40 meter sprint time. McBride et al. [46] revealed that relative strength has a statistically significant relation with 10 and 40 yards sprint times, not with 5 yards sprint times. Moreover, Baker and Nance [14] didn't find a statistically significant relation between 3RM squat values of professional rugby players and 10 and 40 meter sprint times just like Cronin and Hansen [43] determined that there wasn't a statistically significant relation between $3 \mathrm{RM}$ strength value in half squat movement and 5,10 and 30 meter sprint times.In a study performed by Can [25] on amateur athletes, a significant relation was found between $1 \mathrm{RM}$ strength value in full back squat movement and 5 meter sprint time while no relation existed with 30 meter sprint time.

Concerning literature, it seems that some studies were performed to understand which parameters best explain the jumping performance, which is considered as a prerequisite for success in many sports branches. However, there isn't a study investigating the relation of power and velocity parameters in loaded-squat jump exercise applied by using an external load equivalent to $40 \%$ of body weight with the jumping performance. In the studies conducted, it is observed that power and velocity values during lifting applied at different loads of one repetition maximal or the relation between parameters reached during the concentric phase of countermovement jumping exercises or jump squat and jumping performance have been analyzed. For this reason, it is considered that the results obtained are highly important in that they close a current gap in literature. In this study, no statistically significant relation was found between the VJ and SLJ values of the athletes competing in martial arts and MPV ( $r=, 496 ; r=, 429$; $\mathrm{p}>0.05$, respectively) and PV $(\mathrm{r}=, 300 ; \mathrm{r}=, 223 ; \mathrm{p}>0.05$, respectively) values during the propulsive phase of $\mathrm{SQ}_{\text {Loaded }}$ exercise applied with an external load corresponding to $40 \%$ of the body weight while a positive relation was revealed between MPP $(r=, 620 ; r=, 580$; $\mathrm{p}>0.05$, respectively) and $\mathrm{PP}(\mathrm{r}=, 678 ; \mathrm{r}=, 572 ; \mathrm{p}<0.05$, respectively).

In the study of Requena et al. [22] conducted on football players, the relation between MP and MPP values obtained with an external load reflecting 50, 75, 100 and $125 \%$ of body weight in half squat movement and vertical jumping distance was examined and it was concluded that these variables exhibited significant relation with the jumping distance. It was stated that jumping measurements and mean power value reached at $50 \%$ of only body weight aren't related significantly and the strongest relation is the mean power at $75 \%$ of body weight. However, a significant relation wasn't found between vertical jumping distance and power parameters reached in concentric phase in full back squat movement applied in different 1RM loads in a study of Can [25]. In the study of Çolak et al. [39], a positive relation was obtained between the standing long jump performance and $40 \%, 50 \%$ and $60 \%$ power values of 1RM. Marques and Gonzalez-Badillo [47] stated that there was a moderate relation between jumping height and MP and PP values obtained during propulsive phase of full squat movement. Ashley and Weiss [48] established that there was a significant relation between PP value reached in concentric phase of jump squat movement and vertical jumping height. Similar results were obtained in the studies of various researchers. Dowling and Wamos [49] found a high level relation between PP in concentric phase of jumping and countermovement jumping height and they stated that PP was the most powerful indicator of vertical jumping performance. Gonzales-Badillo and Marques [50] concluded that there was a relation between MP and PP parameters generated in concentric phase of vertical jumping and countermovement jumping height. Regarding the studies, it is observed that power parameters have a significant relation with the jumping distance.

In the study of Lopez-Segovia et al. [24] conducted on football players, it was determined that MP efficiency during the full squat movement applied with an external load of $70 \mathrm{~kg}$ is considerably related to the most of sprint times. Also, a significant relation was obtained between 10 $\mathrm{m}$ sprint time and MP value in full squat movement applied with an external load of 30 and $40 \mathrm{~kg}$. It was determined that there was a significant relation between different sprint times and PP valus in full squat movement applied with an external load of 20 and $30 \mathrm{~kg}$. In another study of Lopez-Segovia et al. [23], a significant relation was obtained between MP value during full squat movement in different loads (30, 40, 50 and $60 \mathrm{~kg})$ and 10,20 and 30 meter sprint times. It was also concluded that sprint times were considerably related to PP values. In a study of Requena et al. [22] conducted on semi-professional football players, a significant relation was ascertained between MPP and PP values obtained with an external load corresponding to $50,75,100$ and $125 \%$ of body weight in half-squat movement with 15 meter sprint time. Çolak et al. [39] stated that 30 meter sprint time had a negatively significant relation with $40 \%(\mathrm{r}=-, 637 ; \mathrm{p}<0.01), 50 \%(\mathrm{r}=$ $-, 623 ; \mathrm{p}<0.01)$ and $60 \%(\mathrm{r}=-, 451 ; \mathrm{p}<0.05)$ power values of one repetition maximal. In the study of Can [25], moderately negative relation was ascertained between 5 
meter sprint time with MP and PP values in 40\% and 70\% of 1RM and MPP values during concentric phase of full squat movement in $70 \%$ of $1 \mathrm{RM}$; between 30 meter sprint time and MP reached in $40 \%$ and $70 \%$ of $1 \mathrm{RM}$, PP reached in $40 \%$ and $60 \%$ of $1 \mathrm{RM}, \mathrm{MV}$ reached in $20 \%$ and $90 \%$ of $1 \mathrm{RM}, \mathrm{PV}$ values reached in $40 \%$ and $60 \%$ of $1 \mathrm{RM}$. No relation was established between the power and velocity parameters in full squat movement applied with other loads and 5 and 30 meter sprint times. In this study, no relation was found between 10,20 and 30 meter sprint times and mean propulsive velocity $(\mathrm{r}=-, 332 ; \mathrm{r}=-, 375 ; \mathrm{r}=-, 446$; $\mathrm{p}>0.05$, respectively), peak velocity $(\mathrm{r}=-, 058 ; \mathrm{r}=-, 118 ; \mathrm{r}=$ ,$- 165 ; \mathrm{p}>0.05$, respectively), mean propulsive power ( $\mathrm{r}=$ ,$- 285 ; \mathrm{r}=-, 482 ; \mathrm{r}=-, 485 ; \mathrm{p}>0.05$, respectively) and peak power $(\mathrm{r}=-, 205 ; \mathrm{r}=-, 512 ; \mathrm{r}=-, 391 ; \mathrm{p}>0.05$, respectively) in propulsive phase of loaded-squat jump exercise. Similarly, in another study of Marqeus et al. [17] conducted on amateur athletes playing in different sports branches (football, futsal, handball), they concluded that MPV and PV values during the countermovement jumping exercise didn't have any statistically significant relation with the 5 meter sprint time. Concerning the results, it is observed that the results obtained from this study don't comply with the other results in literature apart from the results obtained in the study of Marques et al. [17]. The reason for this can be the difference of test procedures in other studies. In the above-mentioned studies, the relations between the sprint performance and velocity and power parameters in full squat and half squat movement by using external loads at different weights were studied.

In conclusion, sprint and jumping performance is accepted as important components of many sports branches and these components are highly effective for success in these sports. Therefore, many training methods are used in increasing power and strength in sports with the purpose of improving physical performance and the performance in such specific branches as sprint and jumping [26,51]. It is observed in literature that the relation between power and velocity values reached in concentric phase of full or half squat movement with sprint and jump performances $[22,23,24,25,39]$ or the relation between velocity parameters in countermovement jumping movement and short sprint performance [17] has been researched. However there is no study examining the relation between sprint and jumping performance with velocity and power parameters during loaded-squat jump movement. Therefore, it is thought that the results obtained are important for the literature of sports sciences and they will be a reference source for future studies. Considering that sprint and jumping performance is deemed as important components in many sports branches and these components are highly important elements for athletic success $[7,26]$, determining the velocity and power values of athletes during jumping movement and some performance characteristics and revealing the relation between them may contribute to the training of these characteristics.

\section{REFERENCES}

[1] Newton, R.U., \& Kraemer, J.W. (1994). Developing explosive muscular power: Implications for a mixed methods training strategy. Strength and Conditioning Association Journal, 16(5), 20-31.

[2] Stone, M.H., Sanborn, K., O'Bryant, H.S., Hartman, M., Stone, M.E., Proulx, C., Ward, B., \& Hruby, J. (2003). Maximum strength-power-performance relationships in college throwers. Journal of Strength and Conditioning Research, 17(4), 739-745.

[3] Ratamess, N. (2012). ACSM'S foundations of strength training and conditioning. Chine: Lippincott Williams \& Wilkins.

[4] Baker, D. (2001). Acute and long-term power response to power training: Observations on the training of an elite power athlete. National Strength and Conditioning Association, 23(1), 47-56.

[5] Cronin, J.B., \& Sleivert, G. (2005). Challenges in understanding the influence of maximal power training on improving athletic performance. Sports Medicine, 35(3), 213-234.

[6] Sanchez-Medina, L., Perez, C.E., \& Gonzales-Badillo, J.J. (2010). Importance of the propulsive phase in strength assessment. International Journal of Sports Medicine, 31(2), 123-129.

[7] Sanchez-Medina, L., Gonzales-Badillo, J.J., Perez, C.E., \& Garcia-Pallares, J. (2014). Velocity and power - load relationship of the bench pull vs. bench press exercises. International Journal of Sports Medicine, 35(3), 209-216.

[8] Baker, D., Nance, S., \& Moore, M. (2001). The load that maximizes the average mechanical power output during jump squats in power-trained athletes. Journal of Strength and Conditioning Research, 15(1), 92-97.

[9] Baker, D., \& Newton, R.U. (2005). Acute effect on power output of alternating an agonist and antagonist muscle exercise during complex training. Journal of Strength and Conditioning Research, 19(1), 202-205.

[10] Zatsiorsky, V. M. (1998). Kinematics of human motion. Champaign, IL: Human Kinetics.

[11] Bartlett, R. (2007). Introduction to sports biomechanics: Analysing human movement patterns ( $2^{\text {nd }}$ edition). Oxon: Routledge.

[12] Kraemer, J.W., \& Vinger, L.J. (2007). Muscle anatomy. In Brown, E.L. (Ed). Strength training: National strength and conditioning association (pp. 3-28). Champaign, IL: Human Kinetics.

[13] Gonzales-Badillo, J. J., \& Sanchez-Medina, L. (2010). Movement velocity as a measure of loading intensity in resistance training. International Journal of Sports Medicine, $31(5), 347-352$.

[14] Baker, D., \& Nance, S. (1999). The relation between 
strength and power in professional rugby league players. Journal of Strength and Conditioning Research, 13(3), 224-229.

[15] Baughman, M., Takaha, M., \& Tellez, T. (1984). Sprint training. National Strength and Conditioning Association, 6(3), 34-36.

[16] Delecluse, C., Van Coppenolle, H., Williems, E., Van Leemputte, M., Diels, R., \& Goris, M. (1995). Influence of high resistance and high velocity training on sprint performance. Medicine and Science in Sports and Exercise, 27(8), 1203-1209.

[17] Marques, M.C., Gil, H., Ramos, R., Costa, A. M., \& Marinho, D.A. (2011). Relationship between vertical jump strength metrics and 5 meters sprint times. Journal of Human Kinetics, 29, 115-122.

[18] Young, W. McLean, B., \& Ardagna, J. (1995). Relationship between strength qualities and sprinting performance. Journal of Sport Medicine and Physical Fittness, 35(1), 13-19.

[19] Hennessy, L., \& Kilty, J. (2001). Relationship of the stretch-shortening cycle to sprint performance in trained female athletes. Journal of Strength and Conditioning Research, 15(3): 326 - 331.

[20] Kraska, J.M., Ramsey, M.W., Haff, G.G., Fethke, N., Sands, W.A., Stone, M.E., \& Stone M.H. (2009). Relationship between strength characteristics and unweighted and weighted vertical jump height. International Journal of Sports Physiology and Performance, 4(4): 461 - 473.

[21] Hedrick, A., \& Anderson, J.C. (1996). The vertical jump: A review of the literatüre and a team case study. National Strength and Conditioning Association, 18(1), 7-12.

[22] Requena, B., Gonzales-Badillo, J.J., Villareal, E.S.S., Ereline, J., Garcia, I., Gapeyeva, H., \& Paasuke, M. (2009). Functional performance, maximal strength, and power characteristics in isometric and dynamic actions of lower extremities in soccer players. Journal of Strength and Conditioning Research, 23(5), 1391-1401.

[23] Lopez-Segovia, M., Marques, M.C., Silva-Dias, P., \& Gonzales-Badillo, J.J. (2009). The use of full squat power test as predictor of sprint running ability in soccer players. Journal of Sports Science and Medicine, 8(S11), 104-105.

[24] Lopez-Segovia, M., Marques, M.C., Tillaar, R.V.D., \& Gonzales-Badillo, J.J. (2011). Relationships between vertical jump and full squat power outputs with sprint times in U21 soccer players. Journal of Human Kinetics, 30, 135-144.

[25] Can, İ. (2014). The Relationship with Sprint and Jump Performances of Kinetics-Kinematics in the Propulsive Phase of Full Squat Movement. Karadeniz Technical University, Institute of Educational Sciences (Doctoral Thesis), Trabzon.

[26] Gabbett, T.J., Johns, J., \& Riemann, M. (2008). Performance changes following training in junior rugby league players. Journal of Strength and Conditioning Research, 22(3), 910-917.

[27] Loturco, I., D’Angelo, R.A., Fernandes, V., Gil, S., Kobal, R., Cal Abad, C.C., Kitamura, K., \& Nakamura, F.Y. (2015). Relationship between sprint ability and loaded / unloaded jump tests in elite sprinters. Journal of Strength and Conditioning Research, 29(3), 758-764.

[28] Cormie, P., McCaulley, G.O., Triplett, N.T., \& McBride, J.M. (2007). Optimal loadig for maximal power output during lower body resistance exercises. Medicine and Science in Sports and Exercise, 39(2), 340-349.

[29] Mackenzie, B. (2015). 101 performance evaluation test. London: Electric Word Plc.

[30] Beachle, T. R., Earle, R. W., \& Wathen, D. (2008). Resistance training. In Beachle, T.R., \& Earle, R.W. (Ed). Essentials of strength training and conditioning ( $3^{\text {rd }}$ edition) (pp. 381-412). Champaign, IL: Human Kinetics.

[31] Earle, R.W., \& Beachle, T.R. (2008). Resistance training and spotting techniques. In Beachle, T.R., \& Earle, R.W. (Ed). Essentials of strength training and conditioning ( $3^{\text {rd }}$ edition) (pp. 325-376). Champaign, IL: Human Kinetics

[32] Boone, T. (2013). Introduction to exercise physiology. United States: Jones and Bartlett Publishers.

[33] Izquierdo, M., Ibanez, J., Hakkinen, K., Kraemer, W.J., Ruesta, M., \& Gorostiaga, E.M. (2004). Maximal strength and power, muscle mass, endurance and serum hormones in weightlifters and road cyclists. Journal of Sports Sciences, 22(5), 465-478.

[34] Wisloff, U., Castagna, C., Helgerud, J., Jones, R., \& Hoff, J. (2004). Strong correlation of maximal squat strength with sprint performance and vertical jump height in elite soccer players. British Journal of Sports Medicine, 38(3), 285-288.

[35] McMillan, K., Helgerud, J., MacDonald, R., and Hoff, J. (2005). Physiological adaptations to soccer spesific endurance training in Professional youth soccer players. British Journal of Sports Medicine, 39(5), 273-277.

[36] Thomas, G.A., Kreamer, W.J., Spiering, B.A., Volek, J.S., Anderson, J.M., \& Maresh, C. M. (2007). Maximal power at different percentages of one repetition maximal: Influence of resistance and gender. Journal of Strength and Conditioning Research, 21(2), 336-342.

[37] Alcaraz, P.E., Romere-Arenas, S., Vila, H., \& Ferragut, C. (2011). Power-load curve in trained sprinters. Journal of Strength and Conditioning Research, 25(11), 3045- 3050.

[38] Iglesias-Soler, E., Carballeira, E., Sanchez-Otero, T., Mayo, X., Jimenez, A., \& Chapman, M.L. (2012). Acute effects of distribution of rest between repetitions. International Journal of Sports Medicine, 33(5), 351-358.

[39] Çolak, R., Ağașçığlu, E., Turanlı, E. (2017). Investigation of the relationship between squat maximum forces and perceptage power values between $30 \mathrm{~m}$ sprint and horizontal jump performance. Journal of Physical Education and Sport Sciences, 4(2), 01-12.

[40] Haff, G.G., Whitley, A., \& Potteiger, J.A. (2001). A brief revier: Explosive exercises and sports performance. National Strength and Conditioning Association, 23(3), 13-20.

[41] McGuigan, M.R., Doyle, T.L.A., Newton, M., Edwards, D.J., Nimphius, S., \& Newton, R.U. (2006). Eccentric utilization ratio: Effect of sport and phase of training. Journal of Strength and Conditioning Research, 20(4), 992-995. 
[42] Augustsson, S.R. (2013). Maximum strength in squats determines jumping height in young female volleyball players. The Open Sports Science Journal, 6(1), 41-46.

[43] Cronin, J.B., \& Hansen, K.T. (2005). Strength and power predictors of sports speed. Journal of Strength and Conditioning Research, 19(2), 349-357.

[44] Harris, N.K., Cronin, J.B., Hopkins, W.G., \& Hansen, K.T. (2008). Relationship between sprint times and the strength/power outputs of a machine squat jump. Journal of Strength and Conditioning Research, 22(3), 691-698.

[45] Wilson, G.J., Murphy, A.J., \& Walshe, A. (1996). The specificity of strength training: The effect of posture. European Journal of Applied Physiology, 73(3-4), 346-352.

[46] McBride, J.M., Blow, D., Kirby, T.J., Haines, T.L., Dayne, A.M., \& Triplett, T. (2009). Relationship between maximal squat strength and five, ten, and forty yard sprint times. Journal of Strength and Conditioning Research, 23(6), 1633-1636.

[47] Marques, M.C., \& Gonzales-Badillo, J.J. (2011).
Relationship between strength parameters and squat jump performance in trained athletes. Journal Motricidade, 7(4), $43-48$.

[48] Ashley, C.D., \& Weiss, L.W. (1994). Vertical jump performance and selected physiological characteristics of women. Journal of Strength and Conditioning Research, $8(1), 5-11$.

[49] Dowling, J.J., \& Vamos, L. (1993). Identification of kinetic and temporal factors related to vertical jump performance. Journal of Applied Biomechanics, 9(2), 95-110.

[50] Gonzales-Badillo, J.J., \& Marques, M.C. (2010). Relationship between kinematic factors and countermovement jump height in trained track and field athletes. Journal of Strength and Conditioning Research, 24(12), 3443-3447.

[51] Santos, E.J.A.M., \& Janeira, M.A.A.S. (2008). Effects of complex training on explosive strength in adolescent male basketball players. Journal of Strength and Conditioning Research, 22(3), 903-909. 